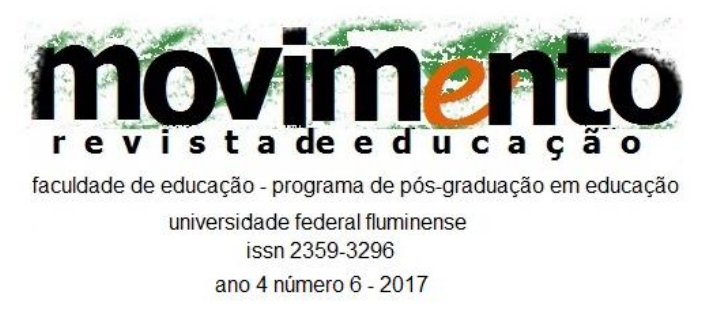

\title{
A EMOÇÃO DE ESTAR EM ANGICOS/RN - 54 anos depois
}

\author{
Cláudia Cristina Andrade ${ }^{1}$ \\ Inez Helena Muniz Garcia ${ }^{2}$ \\ Cecilia M. A. Goulart ${ }^{3}$
}

Viajar para Angicos em tempos de tantas perdas para o povo brasileiro, provocadas pelo projeto neoliberal que assola o mundo, e impede a continuidade das propostas que garantiam maior justiça social, significa recuperar o sentido da existência, que não se faz sem luta contra a opressão. Paulo Freire nos chama à luta, através do diálogo e da coerência entre o pensar e fazer educação. Imbuído dessa perspectiva, o Sindicato dos Trabalhadores em Educação Pública do Rio Grande do Norte (SINTE/RN), promove, desde 2013, o Seminário Internacional Diálogos com Paulo Freire. A coordenadora geral do evento é Inez Helena Muniz Garcia que, tendo realizado os cursos de mestrado e doutorado no Programa de Pós-Graduação em Educação/UFF, segue participando do grupo de pesquisa Linguagem, cultura e práticas educativas, no mesmo Programa.

A primeira edição do Seminário teve como principal objetivo comemorar os 50 anos da experiência de alfabetização em Angicos. Como ápice das comemorações, a visita à cidade de Angicos, com o intuito de colocar-nos de

\footnotetext{
1 Doutora em Educação/USP. Professora Adjunta do Instituto de Aplicação Fernando Rodrigues da Silveira (CAp/UERJ). Líder do Grupo de Estudos em Práticas educativas, juventudes e infâncias (GEPEJI). Professora credenciada no Programa de Pós-Graduação em Ensino de Educação Básica/CAp UERJ. claudiandrade1466@gmail.com.

2 Doutora em Educação/UFF. Fundação Banco do Brasil, Programa BB Educar (aposentada). Pesquisadora no grupo Linguagem, cultura e práticas educativas/Programa de Pós-Graduação em Educação/UFF. inezhmg@gmail.com.

${ }^{3}$ Doutora em Letras/PUC-Rio. Professora titular da Faculdade de Educação da Universidade Federal Fluminense/UFF. Líder do grupo de pesquisa Linguagem, cultura e práticas educativas/ Programa de Pós-Graduação em Educação/UFF. goulartcecilia@uol.com.br.
} 


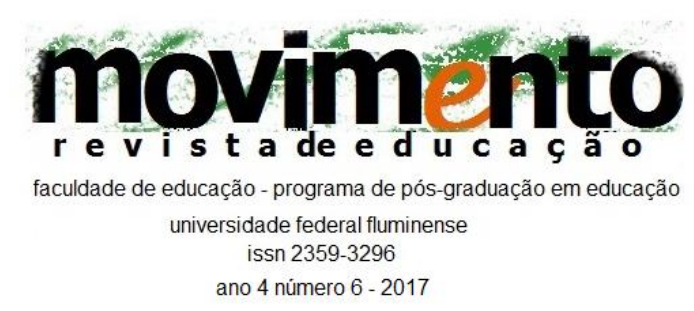

frente para a história, ao permitir conhecermos os que de perto, muito perto, viveram a experiência que inaugurou um outro olhar para a proposta de alfabetização de pessoas jovens e adultas. A beleza do encontro provocou o desejo de repetição. Nos anos seguintes, 2014 e 2015, foram realizados o segundo e o terceiro seminários, sempre com a emocionante visita à cidade de Angicos.

2016, o ano que não deveria ter existido, foi a lacuna sentida, repleta de significados. Em agosto de 2017, foi realizado o IV Seminário Internacional Diálogos com Paulo Freire, marcado pela resistência a um projeto de poder que tenta destruir conquistas históricas. Paulo Freire presente, com sua história, sua esperança, seu olhar humanizante, que nos fortalece contra as injustiças. Conforme constou no texto de chamada ${ }^{4}$ para o IV Seminário Internacional Diálogos com Paulo Freire, a ideia, em 2017, era a contraposição à situação

[...] político-econômico-social que vivemos, abrindo o diálogo sobre o porquê, o para quê e o para quem estão sendo promovidas reformas educacionais, sobre 0 papel dos movimentos sociais e institucionais, o que cabe a cada um de nós discutir, fazer, pensar. Como nos disse Paulo Freire, há momentos em que é preciso entender a cidade e compreender "por que" as coisas chegaram a ser assim como estão. É preciso pessoas mergulhadas na transformação e enfrentamento, é preciso pessoas que leiam a história e a formação dos bairros, das cidades e de suas ciências.

A proposta se fez urgente, tendo em vista a situação que exige reflexão e ação, respostas a um processo galopante de dominação neoliberal. Fez-se, então, um encontro em que "a reflexão sobre os processos educacionais está no cerne de novas possibilidades [...] com produção de crítica e saberes que saiam das pesquisas e dialoguem com os demais saberes da sociedade". E em que houve

\footnotetext{
4 Disponível em <https://dialogospaulofreire.wixsite.com/dialogos2017/copia-submissao-detrabalhos>
} 


\section{movimento \\ faculdade de educação - programa de pós-graduação em educação \\ universidade federal fluminense \\ issn 2359-3296 \\ ano 4 número 6 - 2017}

a aposta "na cultura popular, nos movimentos emancipatórios, no sonho, no desejo" (idem).

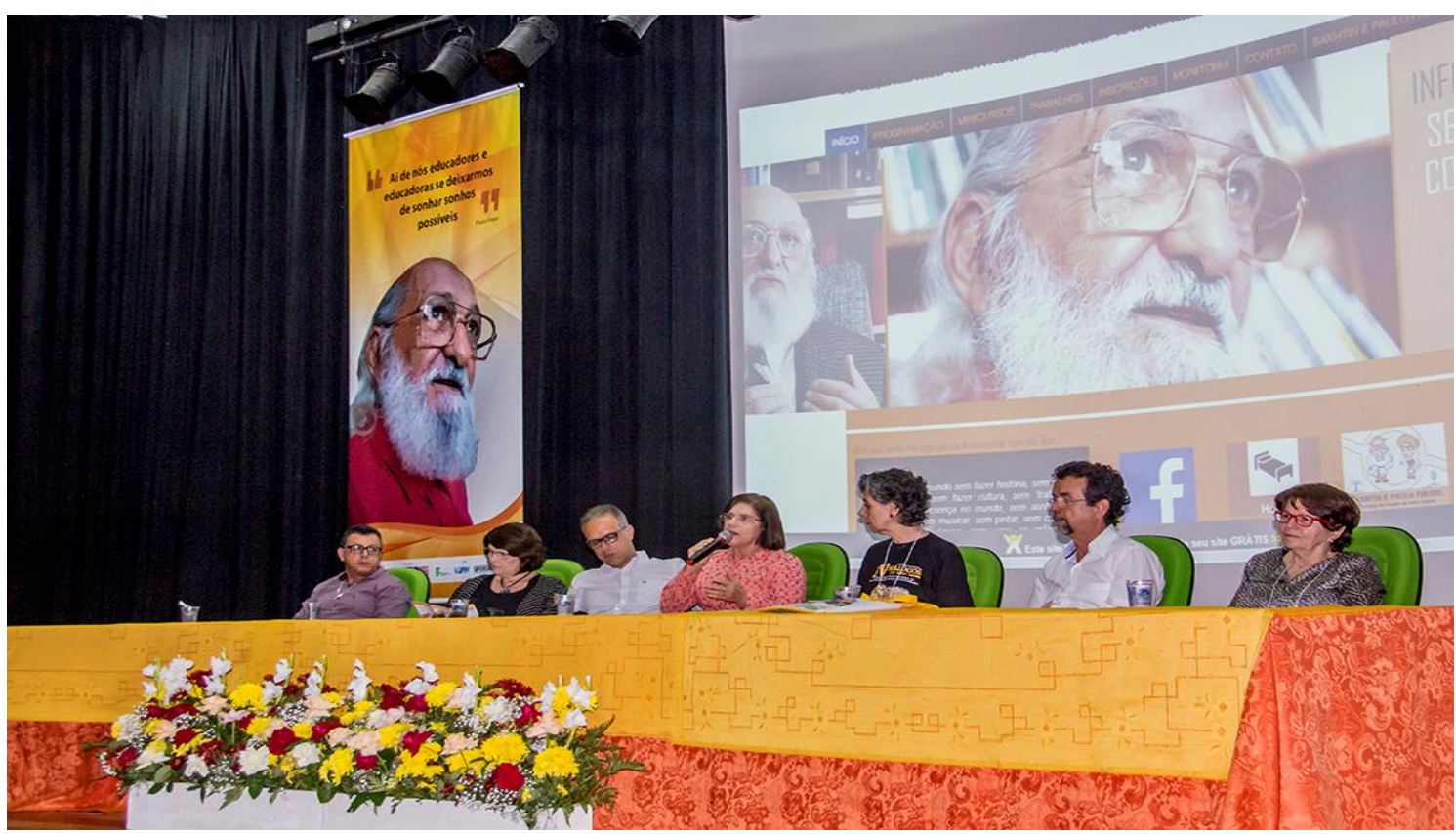

Imagem 1: Abertura do IV Seminário Internacional Diálogos com Paulo Freire, Angicos/RN, 2017. Auditório do IFRN, Campus Natal Central/RN. Da direita para a esquerda: Vilma Gerusa de Oliveira (Assistente Parlamentar, Representante do Mandato da Senadora Fátima Bezerra), Deputado Estadual Fernando Mineiro/RN, Inez Helena Muniz Garcia (Coordenadora Geral do IV Seminário Internacional Diálogos com Paulo Freire), Maria de Fátima Cardoso (Coordenadora Geral do SINTE/RN), Márcia Maria Gurgel Ribeiro (Diretora do Centro de Educação da UFRN),José Arnóbio de Araújo Filho (Diretor-Geral do Campus Natal-Central), Lonaldo Tomaz da Silva (Representante da CUT/RN). (Fonte: SINTE-RN Sindicato dos Trabalhadores em Educação do Rio Grande do Norte).

Ir para Angicos, como nos demais encontros, foi uma grande injeção de força, uma experiência, no sentido que Benjamin empresta a essa palavra, "fato de tradição, tanto na vida coletiva quanto na vida particular [...] dados acumulados, não raro inconscientes, que confluem na memória" (BENJAMIN, 1980, p. 30). Como um ritual, atinge os sentidos/sentimentos dos participantes do evento. Transforma-se em matéria subjetiva, interligando pessoas que, distantes no cotidiano, passam a compartilhar o rito. 


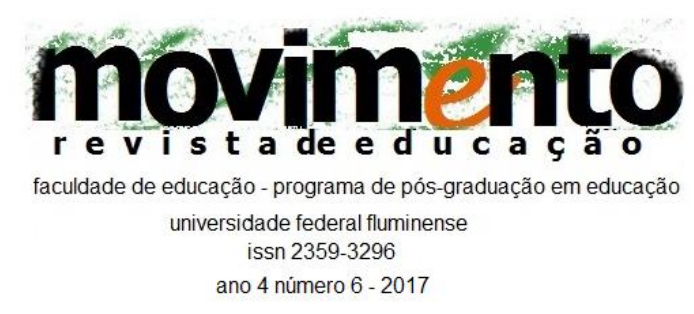

Viajamos de ônibus rumo a Angicos no sábado, dia 2 de setembro de 2017, bem cedo, partindo de Natal, já que a programação estava marcada para iniciar às $9 \mathrm{~h}$ na UFERSA - Universidade Federal Rural do Semi-Árido. Mesmo entre aquelas/es que haviam estado na cidade em anos anteriores, a alegria de voltar e reviver histórias de alfabetização com Paulo Freire era muito grande. Da parte daquelas/es que viviam a experiência pela primeira vez, a emoção se destacava, tomando a todos. O seminário aconteceu no Campus Angicos da UFERSA uma das 18 universidades federais construídas durante os governos Lula e Dilma. $O$ clima era de festa, com muitas/os professoras/es e estudantes nos aguardando. Professoras e professores de países vários - Portugal, Estados Unidos, Cuba, Colômbia -, de quase todos os estados brasileiros, do Acre ao Rio Grande do Sul, e de muitos municípios do RN, num auditório lotado, numa manhã de sábado, debatem, refletem e concordam que a prática é o lugar onde se produz o concreto e a luta, a militância por uma educação pública de qualidade é o que deve dar sentido à essa prática.

Organizamos um semicírculo, de forma que as pessoas, ex-alunas/os de Paulo Freire, sentassem para uma conversa com o público presente, ansioso por conhecer a história da experiência das 40 horas de alfabetização contadas pelos que dela participaram. E elas/es chegaram, sentaram-se conosco. Homens e mulheres, idosas/os, ricos de histórias e vivências.

Neste ponto precisamos destacar que, apesar de as pessoas não terem sido exalunos e ex-alunas diretamente de Paulo Freire, e sim das/os monitoras/es que desenvolveram o método sob a orientação do educador, eles e elas são reconhecidas como os alunos e alunas de Paulo Freire. E assim passamos a chamá-las neste texto, pois compreendemos que a experiência vivida se tornou marca indelével (por isso não usamos o prefixo "ex"), não da ação de cada monitor/a propriamente, mas daquilo que foi pensado como proposta prática, metodologicamente organizada, a partir da orientação e supervisão de Freire. 


\section{movimento \\ faculdade de educação - programa de pós-graduação em educação universidade federal fluminense issn 2359-3296 \\ ano 4 número 6 - 2017}

Não queremos, com isso, desconsiderar a importância de cada jovem monitor/a, carinhosamente lembradas/os durante a conversa, mas reforçar a permanência da experiência e da importância de manter o que foi sendo nomeado pelas pessoas que dela participaram.

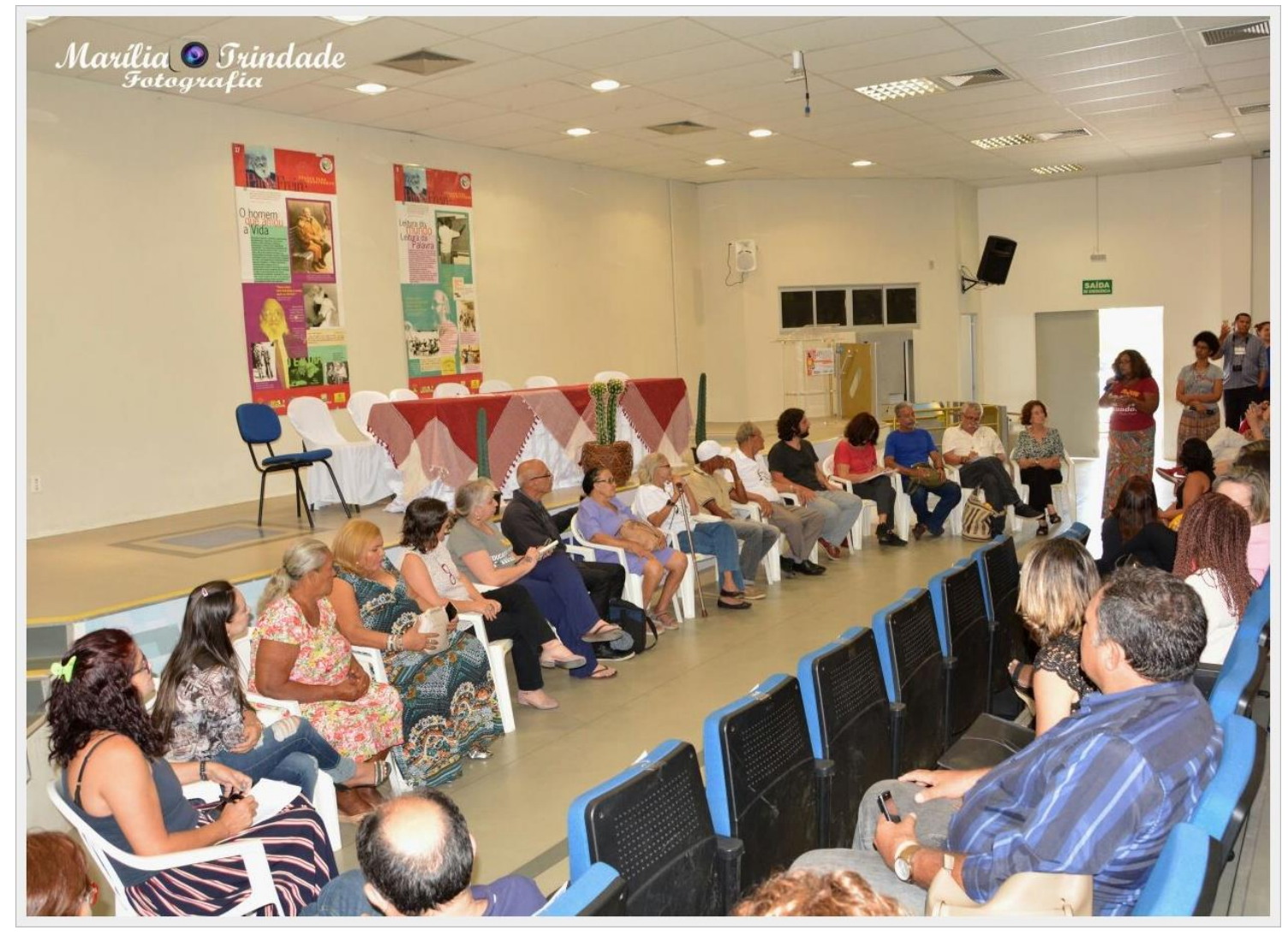

Imagem 2: Roda de Conversa no IV Seminário Internacional Diálogos com Paulo Freire, Angicos/RN, 2017. Roda de conversa com alunos e alunas de Paulo Freire, no auditório da UFERSA, Angicos/RN. A quarta pessoa, da esquerda para direita, de vestido estampado em tons de verde, é Neide. A senhora que está à frente da mesa, segurando uma bengala, é Dona Maria; ambas foram citadas no texto. As alunas e os alunos de Paulo Freire estão na roda, juntamente com o público que lá estava para participar do evento. (Fonte: fotografia Marília Trindade. Acervo das autoras).

Dialogar com os alunos de Paulo Freire nos faz lembrar o início de sua primeira carta, Carta de Paulo Freire aos professores (2001):

Nenhum tema mais adequado para constituir-se em objeto desta primeira carta a quem ousa ensinar do que a significação crítica desse ato, assim como a significação igualmente crítica de aprender. É que não existe ensinar sem 


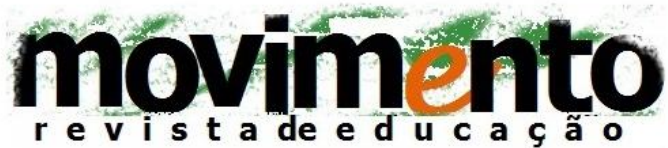 \\ faculdade de educação - programa de pós-graduação em educação \\ universidade federal fluminense \\ issn 2359-3296 \\ ano 4 número 6 - 2017}

aprender e com isto eu quero dizer mais do que diria se dissesse que 0 ato de ensinar exige a existência de quem ensina e de quem aprende. Quero dizer que ensinar e aprender se vão dando de tal maneira que quem ensina aprende, de um lado, porque reconhece um conhecimento antes aprendido e, de outro, porque, observado a maneira como a curiosidade do aluno aprendiz trabalha para apreender o ensinando-se, sem o que não o aprende, o ensinante se ajuda a descobrir incertezas, acertos, equívocos (FREIRE, 2001, p.1).

Sentir as mulheres e os homens que ali se apresentavam à vontade para falar de suas experiências, manifestando-se com simplicidade, espontaneidade e sabedoria. Ouvi-los fazia ecoar a criticidade do ato de ensinar-aprender.

Eclea Bosi (1994, p.43), importante pesquisadora que nos deixou há pouco, nos fez compreender, com suas pesquisas, o valor irredutível da memória dos mais velhos, que conseguem, com sua narrativa, remontar tempos que nos constituem e que a pressa da cidade nos faz esquecer. Para ela, "o narrador tira o que narra da própria experiência e a transforma em experiência dos que o escutam". Assim, a cada ano, ao final do Seminário Internacional Diálogos com Paulo Freire, somos levadas/os para aquele tempo mágico, em que um sonho ia se tornando um fazer.

Em abril de 1963, essas pessoas que lá estavam foram testemunhas de uma história. Para muitas/os, a mais importante história na educação brasileira. Porque carrega consigo o que há de mais importante no ser humano: sua humanidade, seu direito de ser, de viver coisas boas da vida, como nos disse Neide, professora que, como Paulo Freire, luta pelo direito de cada criança, cada homem, cada mulher, ter direitos: à arte, à leitura, ao conforto da certeza da comida. Neide tinha seis anos à época das aulas de Freire, em 1963. Participava das aulas no colo do pai, que se alfabetizava. Acompanhava o pai. E nesse acompanhar, também se alfabetizou. Essa história Neide nos contou emocionada, defendendo que todas/os deveriam poder se alfabetizar no colo do pai. A vivência foi tão marcante que ela a deseja para todas as pessoas. Dona 


\section{movimento \\ faculdade de educação - programa de pós-graduação em educação universidade federal fluminense issn 2359-3296 \\ ano 4 número 6 - 2017}

Maria, por sua vez, lembra que frequentava as aulas escondida da família, até que foi dedurada pela irmã e teve que enfrentar o pai. Este chamava a atenção dela de que aquele lugar não era para ela, era um lugar de comunistas. E ela reagiu à fala do pai afirmando que se as pessoas que coordenavam a atividade eram comunistas, eram muito boas e que ela estava gostando muito e continuaria a participar do grupo. Dona Maria é a senhora que aparece na penúltima foto.

Assim, a experiência delas e deles passa a viver em nós, a fazer parte do nosso discurso, da nossa vida, e da forma como a vemos. Lembra-nos que nós temos direitos e, com Marias, Neides e Freires, seguimos lutando. O mundo não é, está sendo, nos ensinou o mestre.

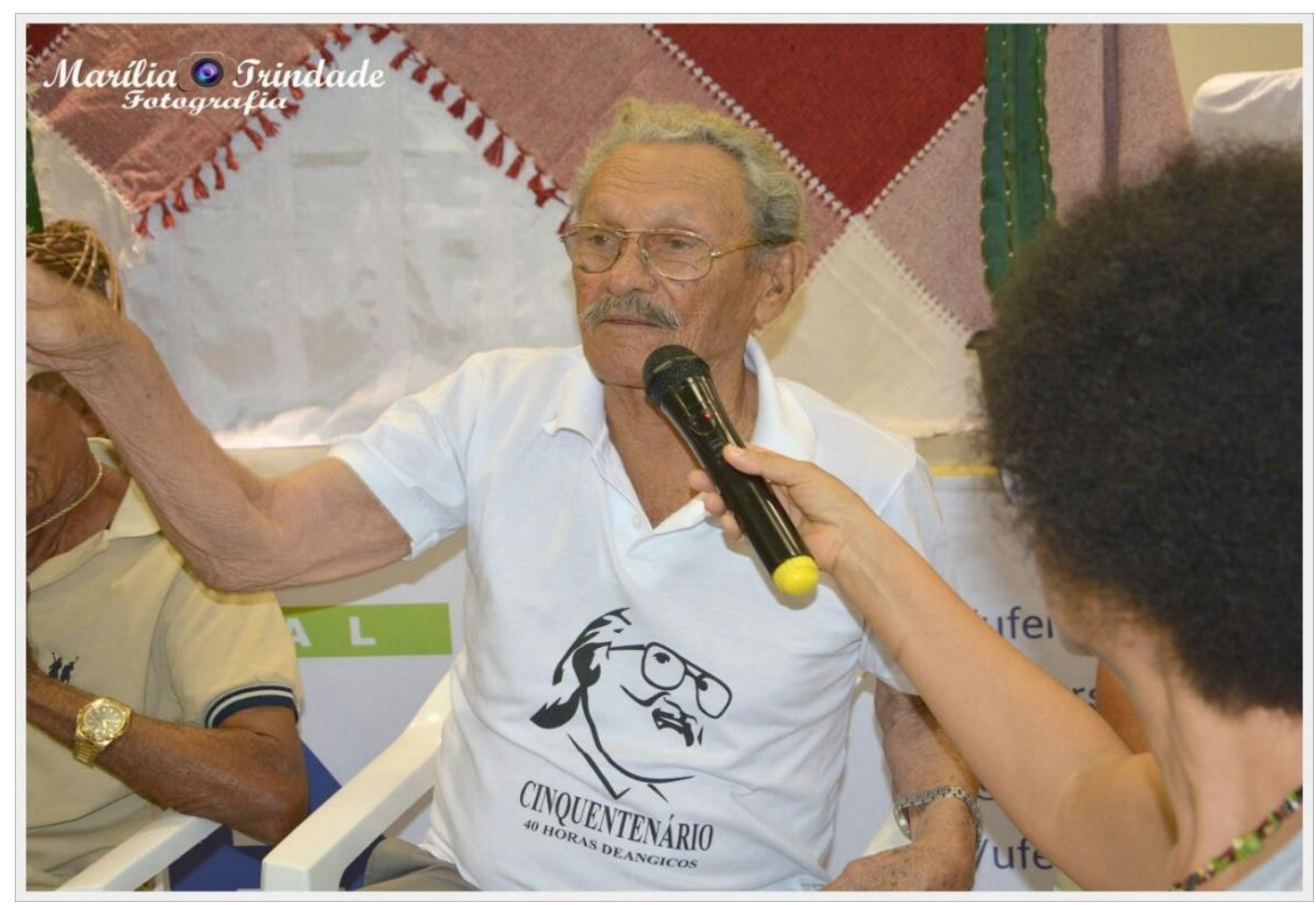

Imagem 3: Sr. Geraldo, aluno de Paulo Freire, no IV Seminário Internacional Diálogos com Paulo Freire, Angicos/RN, 2017. (Fonte: Acervo das autoras. Fotografia Marília Trindade). 


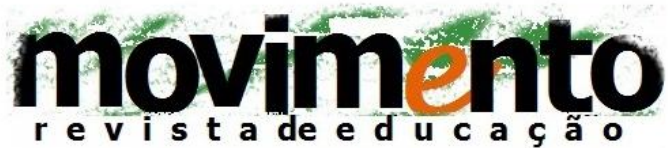 \\ faculdade de educação - programa de pós-graduação em educação universidade federal fluminense issn 2359-3296 \\ ano 4 número 6 - 2017}

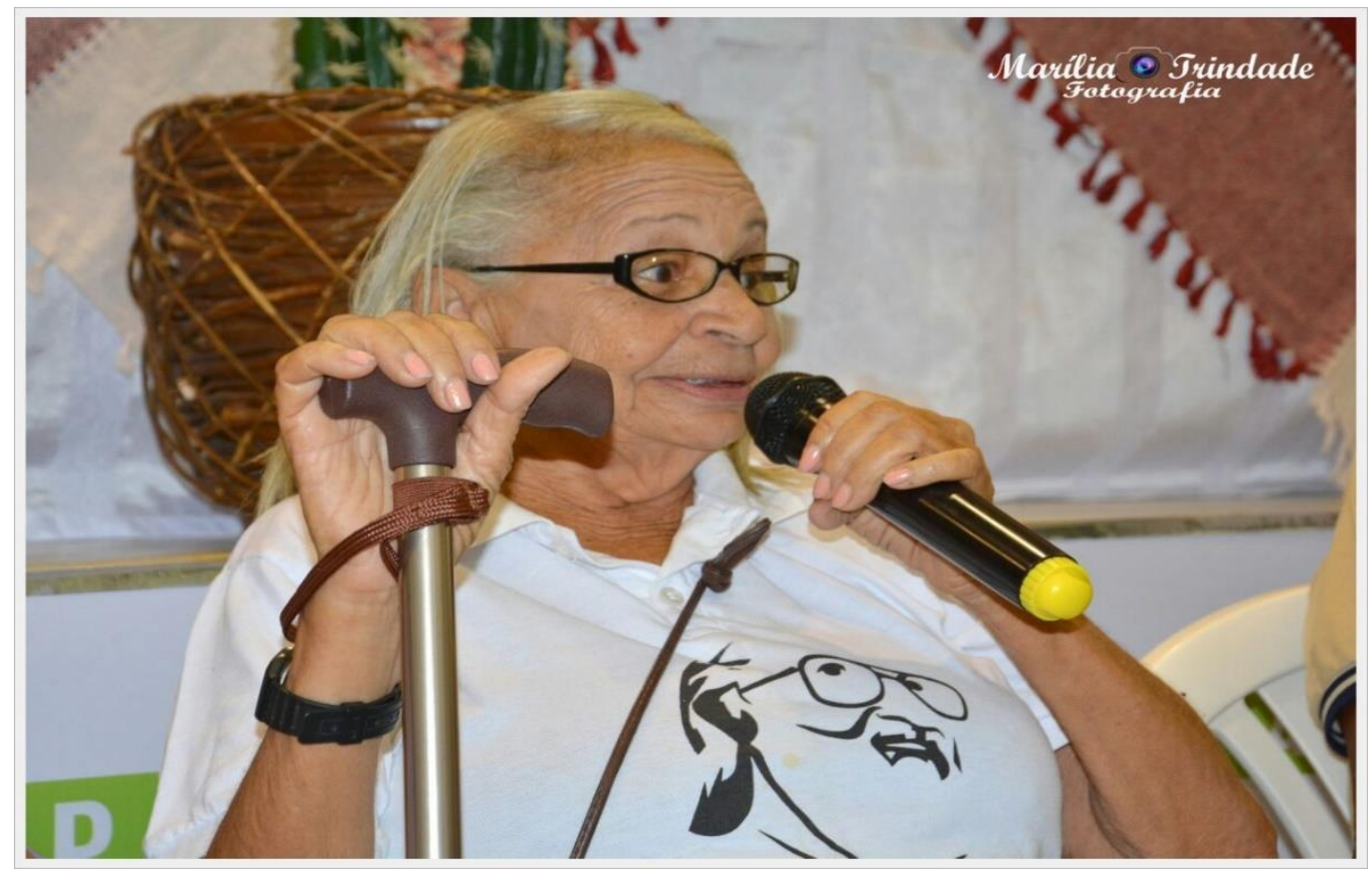

Imagem 4: Dona Maria, aluna de Paulo Freire, no IV Seminário Internacional Diálogos com Paulo Freire, Angicos/RN, 2017. (Fonte: Acervo das autoras. Fotografia Marília Trindade).

Estamos tão envolvidos/as com formas dominantes de conhecimentos que muitas vezes olhamos para as pessoas pela ótica da falta, pela ótica do que elas não sabem. Na escola, essa questão não é nova, e parece que precisa continuar a ser enfrentada. $O$ que as pessoas sabem? Paulo Freire nos remete ao espaço fundamental desses saberes, de seu desvelamento e do diálogo com os conhecimentos de mundo. Com os alunos e alunas de Paulo Freire, passamos a ser cúmplices de suas histórias, quando partilhamos seus saberes: os medos de alguns pais daquela época, que proibiam a participação de seus filhos na "experiência comunista"; da coragem da menina que guardou sob o colchão o material considerado subversivo a partir do golpe militar, revelando a importância que tinha para ela cada um daqueles cadernos; do rapaz que aprendeu junto com os guardas, dentro da cadeia, que também serviu como sala de aula; da menina que aprendeu no colo do pai, junto com ele e com sua mãe, e hoje se 


\section{movimento \\ faculdade de educação - programa de pós-graduação em educação \\ universidade federal fluminense \\ issn 2359-3296 \\ ano 4 número 6 - 2017}

orgulha de ser professora; daqueles e daquelas que, deixando de lado o analfabetismo, e aprendendo a ler, tanto um pouco das palavras quanto um tanto do mundo, reconheceram que as injustiças poderiam ser desfeitas pela ação do povo, e se orgulham dos filhos e filhas que ajudaram a formar, na palavramundo.

A emoção tomou conta de todos e todas que estiveram participando e dialogando em Angicos, pessoas de todas as idades. Lá, naquelas terras, um importante encontro - político, cultural, histórico -, um dia aconteceu com Paulo Freire. E agora, de outra forma, voltava a acontecer. A emoção foi vivida com uma ponta de tristeza também pelos anos passados sem que esse projeto tenha continuado... E nos lembra da história que nos assola, tristemente cíclica, em que a criatividade e a sabedoria de todos criam métodos, formas, políticas, ações, teorias que tão rapidamente são interrompidas pela mão suja dos que se locupletam da pobreza, da miséria, da falta, da dor. Mas, ao mesmo tempo, ficamos compreendendo, na forma de um saber de experiência feito, que o que foi criado não desaparece. Sua força reside em sua permanência, nas vidas, nas histórias, nas lendas, nas redescobertas.

Angicos nos fortalece, e nesses tempos de exceção, de ruptura democrática, nos ajuda a desafiar o medo, que se apresenta com muitas faces. A Paulo Freire nos aliamos e bradamos:

De anônimas gentes, sofridas gentes, exploradas gentes aprendi sobretudo que a paz é fundamental, indispensável, mas que a paz implica lutar por ela. A paz se cria, se constrói na construção incessante da justiça social. Por isso, não creio em nenhum esforço chamado de educação para a paz que, em lugar de desvelar o mundo das injustiças o torna opaco e tenda a miopizar as suas vítimas (FREIRE, A. M., 2006, p. 390). 


\section{movimento \\ faculdade de educação - programa de pós-graduação em educação \\ universidade federal fluminense \\ issn 2359-3296 \\ ano 4 número 6 - 2017}

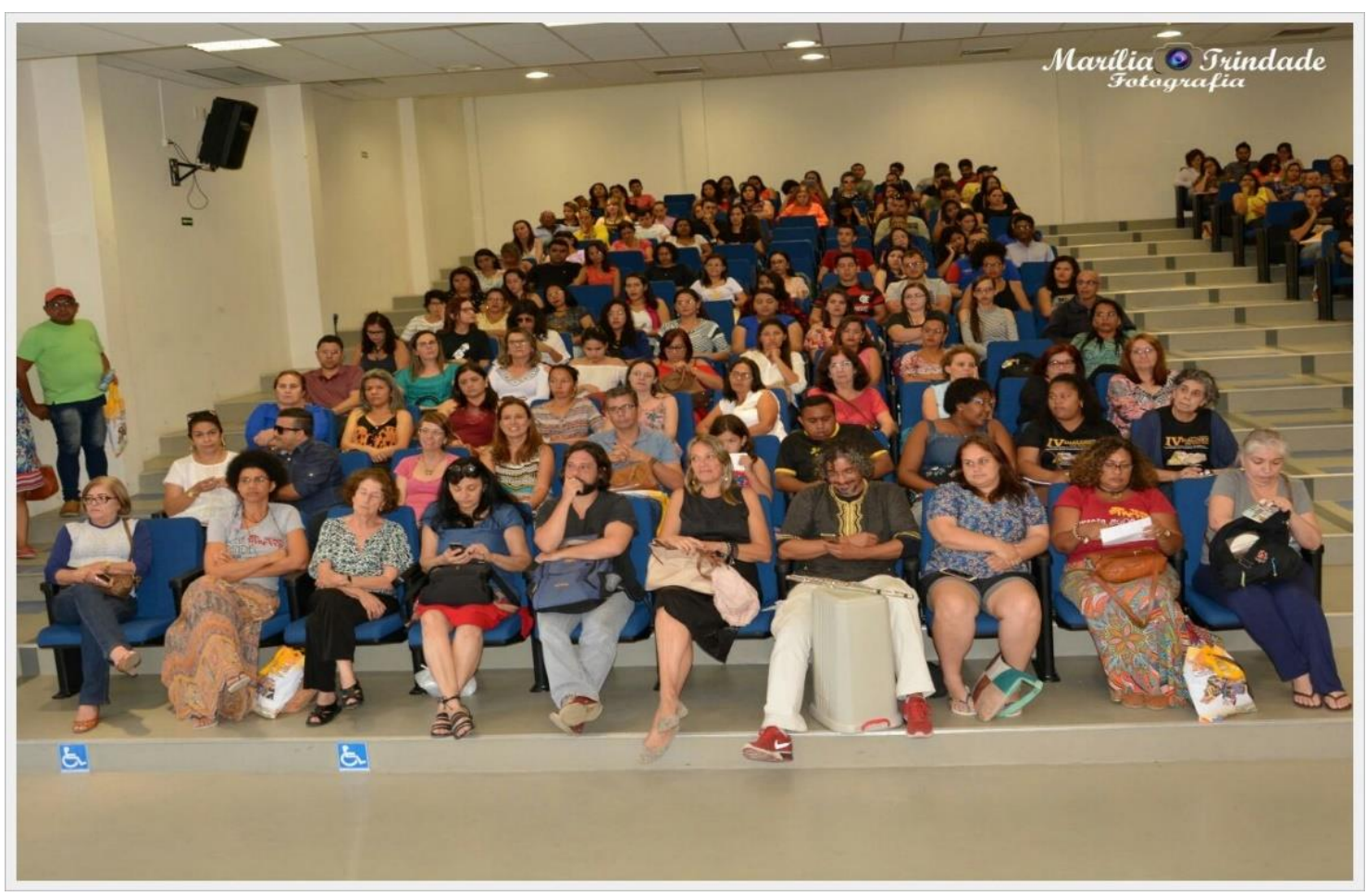

Imagem 5: Visão parcial da ocupação do auditório em Angicos/RN, 2017. (Fonte: Acervo das autoras. Fotografia Marília Trindade)

\section{Referências}

BENJAMIN, W. Sobre alguns temas em Baudelaire. São Paulo: Abril Cultural, 1980. p 29-56. (Coleção Os pensadores).

BOSI, E. Memória e sociedade: lembrança de velhos. São Paulo: Companhia das Letras, 1994.

FREIRE, P. Política e educação. Indaiatuba: Villa das Letras, 2007.

. Carta de Paulo Freire aos professores. Estudos avançados, n. 15, vol. 42, 2001.

FREIRE, A. M. Educação para a paz segundo Paulo Freire. Revista Educação. Pontifícia Universidade Católica do Rio Grande do Sul, Porto Alegre: PUC/RS, ano XXIX, n. 2, p. 387-393, mai./ago. 2006.

Recebido em: 30.09 .2017

Aceito em: 18.10.2017 